\title{
Association Between Parents' Smoking Status and Tobacco Exposure in School-Age Children: Assessment Using Major Urine Biomarkers
}

\section{Sung Hoon Jeong}

Department of Public Health, Graduate School, Yonsei University

\section{Bich Na Jang}

Department of Public Health, Graduate School, Yonsei University

\section{Soo Hyun Kang}

Department of Public Health, Graduate School, Yonsei University

Jae Hong Joo

Department of Public Health, Graduate School, Yonsei University

Eun-Cheol Park ( $\nabla$ ecpark@yuhs.ac)

Department of Preventive Medicine, Yonsei University College of Medicine

\section{Research Article}

Keywords: NNAL, smoke, biomarkers

Posted Date: November 30th, 2020

DOl: https://doi.org/10.21203/rs.3.rs-107977/v1

License: (c) (i) This work is licensed under a Creative Commons Attribution 4.0 International License.

Read Full License

Version of Record: A version of this preprint was published at Scientific Reports on February 25th, 2021.

See the published version at https://doi.org/10.1038/s41598-021-84017-y. 


\section{Abstract}

Children are at risk of exposure to secondhand smoke. We aimed to evaluate the extent of their exposure to it in relation to their parents' smoking status by using biomarkers relevant to smoking. We evaluated 847 school-age children (6-12 years) who lived with their parents, using data from the Korea National Health and Nutrition Examination Survey 2016-2018. Secondhand smoke exposure in children of nonsmoking and smoking parents was assessed by measuring urinary 4-(methylnitrosamino)-1-(3-pyridyl)-1butanol (NNAL) and cotinine concentrations. Overall, the parents of $482(55.1 \%)$ children smoked and those of $392(44.9 \%)$ children did not smoke. After adjusting for covariates, significantly higher concentrations of NNAL $(\beta=0.482$, standard error [S.E.] $=0.065, P<0.001)$ and cotinine $(\beta=0.472, S . E .=0.06$, $P<0.001)$ were found in children of smoking parents than in children of non-smoking parents. Children of parents who smoked a higher number of cigarettes showed higher NNAL and cotinine concentrations than children of non-smoking parents. Children with both parents who smoked showed the highest NNAL and cotinine concentrations. Children of smoking parents are at a higher risk of exposure to secondhand smoke. A smoke-free environment must be maintained to protect children from the harmful effects of secondhand smoke. Therefore, comprehensive national anti-smoking policies are required.

\section{Introduction}

Individuals exposed to secondhand smoke (SHS) are subject to >250 carcinogens and toxic chemicals $[1,2]$. Exposure to SHS is as harmful as smoking itself because it can cause diseases, such as lung cancer, cardiovascular disorders, and chronic diseases, among non-smokers [3]. Approximately 603,000 individuals, including children, die each year from SHS exposure, accounting for approximately $1.0 \%$ of the global mortality rate [4].

Children are especially vulnerable to SHS [5,6]. Exposure to SHS in children leads to early death [7] and increases the risk of sudden infant mortality syndrome [8], acute respiratory infections, and severe asthma symptoms [9-11]. SHS exposure is also associated with severe adverse health effects, such as the slowing of lung growth in children. At the global level, around $40 \%$ of children are still exposed to SHS at home or other places frequently visited by children, and most exposures are related to parental smoking [12]. Recently, there have been considerable efforts to prevent children from being exposed to SHS. Most people are aware of the harmful effects of SHS, and some smokers adopt measures to protect their children from SHS exposure, such as smoking outside their homes [13,14].

Despite these efforts, there is a growing concern regarding thirdhand smoke (THS) exposure. THS exposure is described as the intake of chemicals produced by smoking that are absorbed into surfaces, such as walls, furniture, or house dust, and released back into the air over a long period of time. THS exposure could result in the bodily absorption of new toxic substances produced from reactions between chemicals [13]. While most individuals tend to refrain from smoking in the company of children, some parents consider it acceptable to smoke nearby, on the balcony or near the window. This may lead to entry of smoke into the room or its nearby spread, thus exposing children to THS [15]. Efforts to prevent 
SHS and THS exposure alone are insufficient for preventing exposure in children; hence, children may still be exposed to toxic substances.

The major biomarkers of SHS include 4-(methylnitrosoamino)-(3-pyridyl)1-butanol (NNAL) and cotinine, which are metabolites of nicotine. Cotinine is one of the most commonly used tobacco exposure biomarkers in SHS studies and has the advantage of very high specificity and sensitivity in screening tests [16]. NNAL is one of the metabolites of N-nitrosamines, a carcinogen derived from nicotine, and has the advantage of a long half-life of approximately 3 weeks [17]. Many studies have investigated the association between parents' smoking status and SHS exposure biomarkers in children $[10,15,18]$. However, most previous studies have focused on adolescents in terms of smoking probability or on children with certain diseases $[19,20]$.

Thus, this study aimed to investigate the association between parental smoking and NNAL and cotinine concentrations, as biomarkers of SHS exposure, in children. Furthermore, children's NNAL and cotinine concentrations were investigated according to the number of cigarettes smoked and smoking patterns in parents. We targeted school-age children living with their parents and have a low likelihood of smoking on their own, based on the premise that children who live with at least one smoking parent are more likely to be exposed to SHS.

\section{Results}

The mean age was 8.79 years (standard deviation: 1.9); 447 (51.1\%) and 427 (48.9\%) children were male and female, respectively. Table 1 shows the general characteristics of the study population. Of the 874 children, 392 (44.9\%) and $482(55.1 \%)$ had smoking parents and non-smoking parents, respectively. The median NNAL and cotinine concentrations were 1.4 (interquartile range [IQR]: 1.9) and 0.4 (IQR: 0.4) in children with parents who smoked, respectively. Meanwhile, the corresponding values were 0.8 (IQR: 0.9) and 0.2 (IQR: 0.3) in children with parents who did not smoke, respectively.

Table 2 shows the association between children's NNAL and cotinine concentrations and parents' smoking status after adjusting for all confounding variables. There was a positive association between parents' smoking status and children's NNAL $(\beta=0.482$, standard error [S.E.] $=0.065, P<0.001)$ and cotinine $(\beta=0.472, S . E .=0.06, P<0.001)$ concentrations; the association was stronger for smoking parents than for non-smoking parents.

Table 3 shows the results of the subgroup analyses stratified by independent variables. Children's sex and body mass index (BMI), their parents' education level, household income, and type of housing showed positive associations with children's NNAL and cotinine concentrations. Parents currently smoking and with an education higher than college level showed the weakest association with children's NNAL $(\beta=0.407$, S.E. $=0.079, P<0.001)$ and cotinine $(\beta=0.414, S . E .=0.066, P<0.001)$ concentrations. Additionally, parents currently smoking and with the lowest income level tended to show the strongest association with children's NNAL $(\beta=0.762$, S.E. $=0.167, P<0.001)$ and cotinine $(\beta=0.634$, S.E. $=0.155, P<0.001)$ concentrations. 
Fig. 2 shows the association of the number of cigarettes smoked and smoking patterns with the children's NNAL and cotinine concentrations. The higher the number of cigarettes smoked, the higher the children's NNAL and cotinine concentrations. Children of parents who smoked $>20$ cigarettes had the highest NNAL $(\beta=0.825$, S.E. $=0.096, P<0.001)$ and cotinine $(\beta=0.604, S . E .=0.085, P<0.001)$ concentrations. Further, the children's NNAL and cotinine concentrations were also high when only the father (NNAL: $\beta=0.444$, S.E. $=0.066, P<0.001$; cotinine: $\beta=0.443$, S.E. $=0.058, P<0.001$ ) or mother (NNAL: $\beta=0.738$, S.E. $=0.244, P=0.003$; cotinine: $\beta=0.561$, S.E. $=0.241, P=0.009)$ smoked. When both parents smoked, the NNAL $(\beta=1.209$, S.E. $=0.204, P<0.001)$ and cotinine $(\beta=1.111$, S.E. $=0.179, P<0.001)$ concentrations were the highest (Supplementary Table S1).

\section{Discussion}

Most studies on the association between parents' smoking status and SHS exposure biomarkers have focused on adolescents in terms of smoking probability or on children with certain diseases. In this study of school-age children in Korea, at least one out of two children was living with a parent who smoked, and the NNAL and cotinine concentrations were higher in children whose parents were smokers. Further analysis confirmed that the higher the number of cigarettes smoked by both parents, the higher the degree of SHS exposure in children. To the best of our knowledge, no previous study in Asia has evaluated both NNAL and cotinine levels in school-age children to determine the extent of SHS exposure.

Our results are similar to those of previous studies $[19,21]$. While adolescents tend to spend more time outside the home, school-age children spend a lot of time at home and stay close to their parents, suggesting that living with parents who smoke can be a strong predictor of increased exposure to substances included in cigarettes. The highest NNAL and cotinine concentrations were observed in children when both parents smoked. These results were similar to those of previous studies [22,23]. Additionally, although a direct correlation is difficult, compared to when both the parents were nonsmokers, the children's NNAL and cotinine concentrations were higher when only the mother smoked than when only the father smoked. Compared to children of non-smokers, children whose mothers alone smoked or whose both parents were smokers were 2-13 times more likely to be exposed to SHS at home [24]. However, a recent study showed that SHS exposure among adolescents is associated with paternal smoking [17]. In fact, in East Asian countries influenced by Confucianism, the smoking rate in men is higher than that in women. Thus, smoking abstinence by paternal figures is often chosen as the first strategy to reduce children's exposure to indirect smoking $[19,25]$. However, for school-age children, time spent with the mother tends to be more than two-fold longer than the time spent with the father.

Therefore, smoking abstinence in mothers should also be considered [26]. Consistent with the results of previous research $[24,27,28]$, we found that the higher the number of cigarettes smoked, the higher the children's NNAL and cotinine concentrations, regardless of the child's age. This could be because as the number of cigarettes smoked by the parents increased, the amount of harmful substances adhering to their clothes and skin also rose, indirectly exposing the children. 
In the subgroup analysis, the association trend was significant according to sex (male and female), BMI (underweight, normal weight, and overweight), household income (Q1, Q2, Q3, and Q4), and parents' education level (middle school or lower and college or higher). NNAL concentrations were highest in children with normal BMl, followed by in underweight and overweight children. However, cotinine concentrations were highest in underweight children, followed by in children with normal BMI and in overweight children. This is assumed to be due to the amount of nicotine consumed through food, which influenced the urinary concentration of cotinine; in contrast, NNAL is produced mainly through smoking [29]. NNAL and cotinine concentrations were both highest in children from the low-income group. People from this group have less awareness regarding the risks of exposure to SHS; thus, these children may be more vulnerable [30]. The children of parents with a higher level of education had lower NNAL and cotinine concentrations. This supports the premise that education level has a greater influence on SHS exposure than income, and individuals with higher education levels are less likely to smoke and, in cases where they do, are more likely to quit $[30,31]$.

Our research has confirmed that even after controlling SHS exposure at home and in public, many children still faced serious consequences of their parents' smoking habits. This indicates that while the prohibition of smoking at home and in public show a highly negative correlation with children's exposure to SHS [28,30], these policies alone cannot fully protect them from the adverse effects of SHS exposure due to parental smoking. The fact that children living with parents who smoke may explain such a phenomenon because they have a higher degree of exposure to SHS than children of non-smokers, even if they live in a house where indoor smoking is prohibited [32]. The World Health Organization states that there is no safe level of exposure to SHS, a pollutant that causes serious illnesses in adults and children. Hence, the only effective way to protect the population from the harmful effects of exposure to SHS is to maintain a $100 \%$ non-smoking environment [33]. Implementing physical measures or anti-smoking measures at home, such as the opening of windows or doors or removing cigarette smoke using a ventilator fan, is ineffective in preventing children's exposure to cigarette smoke. This is because only a completely non-smoking environment can prevent SHS exposure in the home [12,32]. Furthermore, it is necessary to persuade the family to abstain from smoking. Providing counseling to parents regarding the harmful effects of SHS exposure and recommending that they quit smoking may reduce SHS exposure, but not completely eliminate it. Therefore, a comprehensive national anti-smoking policy is required. This should include the provision of services and implementation of preventive programs to support smoking cessation, including cessation treatment and counseling, strong smoking regulations in public places, and regulations on tobacco prices and taxes.

This study has some limitations. First, we used cross-sectional data. Therefore, the cause and effect and the direction of the relationships observed cannot be determined. Second, the results of this study were based on self-reported data. Thus, the number of cigarettes smoked may have been underestimated or overestimated, and some survey questions may be subject to recall bias. Third, despite our efforts to control for confounding factors, not all covariates affecting NNAL and cotinine concentrations may have been considered. Notwithstanding these limitations, our study has important implications. The results can be generalized because the research was conducted using the nationally representative and highly 
reliable Korea National Health and Nutrition Examination Survey (KNHANES) data. Our findings also support previous results. We targeted school-age children and thus minimized the bias related to smoking status. Further, we controlled for both SHS exposure in public and at home. These factors were not wellconsidered in previous studies. Furthermore, while analyses based on cotinine measurements were commonly performed in previous studies, our research is meaningful in that we additionally analyzed the concentration of NNAL, which has a longer half-life.

Our study demonstrated that children with parents who smoked are at a higher risk of exposure to SHS, implying that individual efforts to avoid smoking in the presence of children may be an insufficient alternative. Comprehensive national anti-smoking policies that include the provision of anti-smoking services are needed. Furthermore, price- and non-price-related measures should be implemented to persuade parents to quit smoking. Furthermore, cessation treatment and counseling and an increase in cigarette prices and taxes are also required.

\section{Methods}

\section{Study population}

This study was based on data from the 2016-2018 KNHANES VII and the secondary analysis of a large dataset. The KNHANES is a nationwide population-based cross-sectional survey conducted annually since 1998 under the direction of the Centers for Disease Control and Prevention of the Ministry of Health and Welfare to accurately assess the national health and nutritional status [34].

The total number of respondents for the 2016-2018 KNHANES was 24,269. Participants who were not matched based on parent-child relationships $(n=1,384)$; had no data on age $(n=21,019)$ for those between 6 and 12 years; and those without data on NNAL levels, cotinine levels, or other independent variables $(n=992)$ were excluded. Finally, a total of 847 participants were included in the study (Fig. 1). KNHANES data is publicly accessible and ethical approval is not required for the use of the data. In addition, as the respondent's information is completely anonymous, prior consent for research purposes was not required.

\section{Variables}

The dependent variables were NNAL and cotinine concentrations, which are biomarkers of indirect smoking exposure. They were used to quantify the children's degree of exposure to SHS. NNAL and cotinine concentrations during the KNHANES were measured in the urine and were analyzed using highperformance liquid chromatography-tandem mass spectrometry using Agilent 1,200 Series with Triple Quadrupole 5500 (AB Sciex, USA) [17,21]. The main independent variable was the parents' smoking status, classified as "smoker" if any one parent replied "yes" or as "non-smoker" if both parents replied "no" to the question "Do you currently identify yourself as a smoker?" Independent variables that were considered to be potential confounding variables included sociodemographic, economic, and healthrelated characteristics, as well as the survey year. Sociodemographic characteristics included children's sex, age, parents' age, education level, type of housing, and region. Economic characteristics included the 
parental household income and ownership of private health insurance. Health-related characteristics included parents' drinking status and children's exposure to SHS at home and in public.

\section{Statistical analysis}

Univariate linear regression was used to assess the relationship between children's NNAL and cotinine concentrations and parents' smoking status; sociodemographic, economic, and health-related variables; and survey year. Prior to the multiple logistic regression analysis, we performed a log-transformation of the NNAL and cotinine values to ensure normality. Multiple regression analysis was performed while controlling for covariates to analyze the association between parental smoking status and logtransformed NNAL and cotinine concentrations in children. We performed subgroup analyses stratified by the parents' smoking status and multiple regression analysis to examine the associations of children's NNAL and cotinine concentrations according to the children's sex and BMI and the parental household income and education level. Furthermore, after adjusting for covariates, we classified the number of cigarettes smoked $(0,<10,10-19$, and $\geq 20)$ and smoking patterns (non-smoking parents, father only, mother only, both parents) and determined their associations with children's NNAL and cotinine concentrations using multiple regression analysis. All statistical analyses were performed using SAS software, version 9.4 (SAS Institute, Inc.). Statistical results were considered significant at a P-value of $<0.05$.

\section{Declarations}

\section{Data availability}

The datasets generated during and/or analyzed during the current study are available in the Korea National Health and Nutrition Examination Survey (KNHANES) 2016-2018,

\section{https://knhanes.cdc.go.kr/knhanes/main.do.}

\section{Author contributions:}

SHJ and BNJ analyzed and interpreted the data. SHJ wrote the manuscript. All authors contributed to the study concept and design, critically revised the manuscript for important intellectual content, and approved the final version of the manuscript.

\section{Competing interests:}

The authors declare no competing interests.

\section{References}

1. International Agency for Reasearch on Cancer. IARC monographs on the evaluation of carcinogenic risks to humans. 2004. 
2. Talhout R, Schulz T, Florek E, van Benthem J, Wester P, Opperhuizen A. Hazardous compounds in tobacco smoke. Int J Environ Res Public Health 2011;8:613-28.

3. Centers for Disease Control and Prevention (US); National Center for Chronic Disease Prevention and Health Promotion (US); Office on Smoking and Health (US). How tobacco smoke causes disease: The biology and behavioral basis for smoking-attributable disease: A report of the surgeon general. 2010.

4. Öberg M, Jaakkola MS, Woodward A, Peruga A, Prüss-Ustün A. Worldwide burden of disease from exposure to second-hand smoke: a retrospective analysis of data from 192 countries. The Lancet 2011;377:139-46.

5. David M. Homa LJN, Brian A. King, Ralph S. Caraballo, Rebecca E. Bunnell, Stephen D. Babb, Bridgette E. Garrett, Connie S. Sosnoff, Lanqing Wang. Vital signs: disparities in nonsmokers' exposure to secondhand smoke - united states, 1999-2012. 2015. p.4.

6. Kang S, Joo J, Jang S, Park E. Association of exposure to secondhand smoke at home with early age at menarche in South Korea. Public Health 2020;185:144-9.

7. Diver WR, Jacobs EJ, Gapstur SM. Secondhand Smoke Exposure in Childhood and Adulthood in Relation to Adult Mortality Among Never Smokers. Am J Prev Med 2018;55:345-52.

8. Anderson. HR, Cook. DG. Passive smoking and sudden infant death syndrome review of the epidemiological evidence. Thorax 1997;52:1003-9.

9. California Environmental Protection Agency: Air Resources Board. Proposed Identification of Environmental Tobacco Smoke as a Toxic Air Contaminant. University of California 2005.

10. Moritsugu KP. The 2006 Report of the Surgeon General: the health consequences of involuntary exposure to tobacco smoke. Am J Prev Med 2007;32:542-3.

11. Cook DG, Strachan DP. Summary of effects of parental smoking on the respiratory health of children and implications for research. Thorax 1999;54:357-66.

12. United States Public Health Service. The health consequences of involuntary exposure to tobacco smoke: a report of the Surgeon General. U S Dept of Health and Human Services Public Health Service Office of the Surgeon General; 2006.

13. Kim J, Yoon J-H, Kim J, Lee W, Kim Y-K, Lee S, et al. Factors Associated with Beliefs among Adults in Korea about the Health Effects of Thirdhand Smoke on Children. Journal of Environmental Health Sciences 2018;44:90-7.

14. Hyland A, Higbee C, Borland R, Travers M, Hastings G, Fong GT, et al. Attitudes and beliefs about secondhand smoke and smoke-free policies in four countries: findings from the International Tobacco Control Four Country Survey. Nicotine \& Tobacco Research 2009;11:642-9.

15. Gehring U, Leaderer BP, Heinrich J, Oldenwening M, Giovannangelo ME, Nordling E, et al. Comparison of parental reports of smoking and residential air nicotine concentrations in children. Occupational and Environmental Medicine 2006;63:766-72.

16. Kang YH, Lee Y-J, Kong S-Y, Lee DH, Yun Y-h. Usefulness of urinary cotinine test to discriminate between smokers and nonsmokers in korean adolescents. The Korean Journal of Laboratory 
Medicine 2004;24:155-9.

17. Vardavas Cl, Fthenou E, Patelarou E, Bagkeris E, Murphy S, Hecht SS, et al. Exposure to different sources of second-hand smoke during pregnancy and its effect on urinary cotinine and tobaccospecific nitrosamine (NNAL) concentrations. Tobacco Control 2013;22:194-200.

18. Rosen LJ, Tillinger E, Guttman N, Rosenblat S, Zucker DM, Stillman F, et al. Parental receptivity to child biomarker testing for tobacco smoke exposure: A qualitative study. Patient Education and Counseling 2015;98:1439-45.

19. Park M-B. Living with parents who smoke predicts levels of toxicant exposure in children. Scientific Reports 2020;10:1-9.

20. Oddoze C, Dubus JC, Badier M, Thirion X, Pauli AM, Pastor J, et al. Urinary cotinine and exposure to parental smoking in a population of children with asthma. Clinical chemistry 1999;45:505-9.

21. Marano C, Schober SE, Brody DJ, Zhang C. Secondhand tobacco smoke exposure among children and adolescents: United States, 2003-2006. Pediatrics 2009;124:1299-305.

22. Sims M, Tomkins S, Judge K, Taylor G, Jarvis MJ, Gilmore A. Trends in and predictors of secondhand smoke exposure indexed by cotinine in children in England from 1996 to 2006. Addiction 2010;105:543-53.

23. Rudatsikira E, Siziya S, Dondog J, Muula AS. Prevalence and correlates of environmental tobacco smoke exposure among adolescents in Mangolia. The Indian Journal of Pediatrics 2007;74:1089-93.

24. Orton S, Jones LL, Cooper S, Lewis S, Coleman T. Predictors of children's secondhand smoke exposure at home: a systematic review and narrative synthesis of the evidence. PLoS One 2014;9:e112690.

25. Wang Y, Yang M, Tian L, Huang Z, Chen F, Hu J, et al. Relationship between caregivers' smoking at home and urinary levels of cotinine in children. International Journal of Environmental Research and Public Health 2014;11:12499-513.

26. Sayer LC, Bianchi SM, Robinson JP. Are parents investing less in children? Trends in mothers' and fathers' time with children. American Journal of Sociology 2004;110:1-43.

27. Hughes SC, Corcos IA, Hofstetter CR, Hovel MF, Irvin VL, Park HR, et al. Children's exposure to secondhand smoke at home in Seoul, Korea. Asian Pac J Cancer Prev 2008;9:491-5.

28. Fernández MF, Artacho-Cordón F, Freire C, Pérez-Lobato R, Calvente I, Ramos R, et al. Trends in children's exposure to second-hand smoke in the INMA-Granada cohort: an evaluation of the Spanish anti-smoking law. Environmental Research 2015;138:461-8.

29. Haufroid V, Lison D. Urinary cotinine as a tobacco-smoke exposure index: a minireview. International Archives of Occupational and Environmental Health 1998;71:162-8.

30. Gatzke-Kopp LM, Willoughby MT, Warkentien SM, O'Connor T, Granger DA, Blair C. Magnitude and chronicity of environmental smoke exposure across infancy and early childhood in a sample of lowincome children. Nicotine \& Tobacco Research 2019;21:1665-72. 
31. Yi O, Kwon H-J, Kim D, Kim H, Ha M, Hong S-J, et al. Association between environmental tobacco smoke exposure of children and parental socioeconomic status: A cross-sectional study in Korea. Nicotine \& Tobacco Research 2011;14:607-15.

32. Hoh E, Hunt RN, Quintana PJ, Zakarian JM, Chatfield DA, Wittry BC, et al. Environmental tobacco smoke as a source of polycyclic aromatic hydrocarbons in settled household dust. Environmental Science \& Technology 2012;46:4174-83.

33. World Health Organization. Protection from exposure to second-hand tobacco smoke: policy recommendations. 2007.

34. Kweon S, Kim Y, Jang M-j, Kim Y, Kim K, Choi S, et al. Data resource profile: the Korea national health and nutrition examination survey (KNHANES). International Journal of Epidemiology 2014;43:69-77.

\section{Tables}

Table 1. General characteristics of the study population 


\begin{tabular}{|c|c|c|c|c|c|c|c|c|}
\hline \multirow[t]{2}{*}{ Variables } & \multirow[t]{2}{*}{$\mathbf{N}$} & \multirow[t]{2}{*}{$\%$} & \multicolumn{3}{|l|}{ NNAL } & \multicolumn{3}{|l|}{ Cotinine } \\
\hline & & & MEDIAN & IQR & $\begin{array}{l}P \\
\text { value }\end{array}$ & MEDIAN & IQR & $\begin{array}{l}P \\
\text { value }\end{array}$ \\
\hline Parents' smoking status & & & & & $<0.001$ & & & $<0.001$ \\
\hline Smoker & 392 & 44.9 & 1.4 & 1.9 & & 0.4 & 0.4 & \\
\hline Non-smoker & 482 & 55.1 & 0.8 & 0.9 & & 0.2 & 0.3 & \\
\hline \multicolumn{9}{|l|}{ Children } \\
\hline Sex & & & & & 0.001 & & & 0.004 \\
\hline Male & 447 & 51.1 & 1.2 & 1.5 & & 0.3 & 0.5 & \\
\hline Female & 427 & 48.9 & 0.9 & 1.1 & & 0.3 & 0.3 & \\
\hline Age $^{*}$ & 8.79 & 1.9 & & & 0.347 & & & 0.695 \\
\hline BMI & & & & & 0.037 & & & 0.052 \\
\hline Underweight & 580 & 66.4 & 1.0 & 1.3 & & 0.3 & 0.4 & \\
\hline Normal & 261 & 29.9 & 1.1 & 1.3 & & 0.4 & 0.4 & \\
\hline Overweight & 33 & 3.8 & 1.7 & 2.5 & & 0.4 & 0.7 & \\
\hline SHSE (house) & & & & & $<0.001$ & & & $<0.001$ \\
\hline Yes & 26 & 3.0 & 2.9 & 7.2 & & 0.8 & 0.9 & \\
\hline No & 848 & 97.0 & 1.0 & 1.3 & & 0.3 & 0.4 & \\
\hline SHSE (public) & & & & & 0.479 & & & 0.629 \\
\hline Yes & 52 & 5.9 & 1.4 & 1.8 & & 0.4 & 0.3 & \\
\hline No & 822 & 94.1 & 1.0 & 1.3 & & 0.3 & 0.4 & \\
\hline \multicolumn{9}{|l|}{ Parents } \\
\hline Household income & & & & & $<0.001$ & & & 0.001 \\
\hline Q1 (low) & 178 & 20.4 & 1.4 & 2.0 & & 0.4 & 0.5 & \\
\hline Q2 & 256 & 29.3 & 1.2 & 1.5 & & 0.3 & 0.4 & \\
\hline Q3 & 221 & 25.3 & 0.9 & 1.2 & & 0.3 & 0.4 & \\
\hline Q4 (high) & 219 & 25.1 & 0.9 & 1.0 & & 0.3 & 0.3 & \\
\hline Type of housing & & & & & $<0.001$ & & & 0.000 \\
\hline Apartment & 659 & 75.4 & 0.9 & 1.2 & & 0.3 & 0.3 & \\
\hline House & 215 & 24.6 & 1.4 & 2.2 & & 0.4 & 0.5 & \\
\hline
\end{tabular}




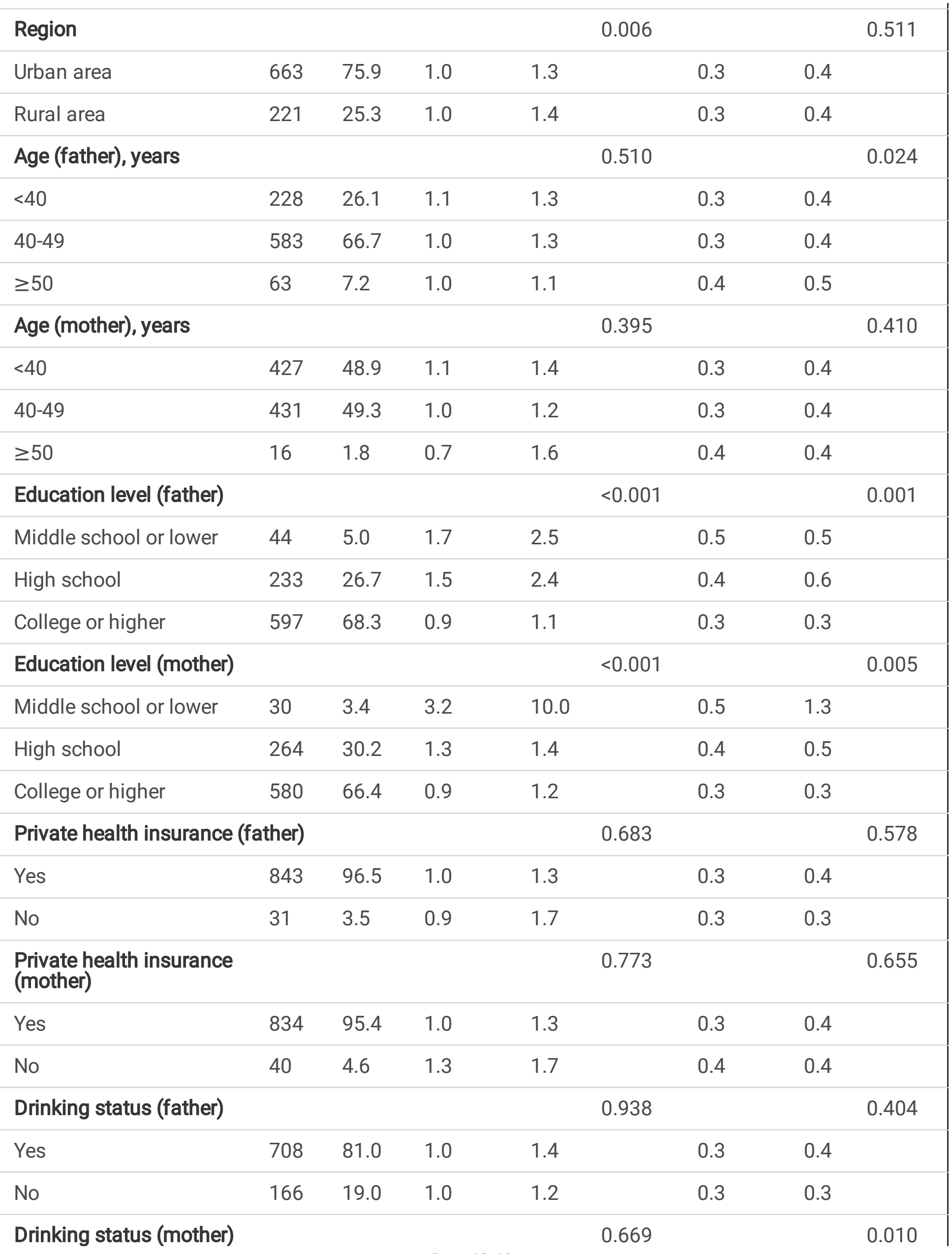




\begin{tabular}{|lrrrrrrr|}
\hline Yes & 497 & 56.9 & 1.0 & 1.4 & 0.4 & 0.4 \\
\hline No & 377 & 43.1 & 1.0 & 1.3 & 0.3 & 0.3 & 0.557 \\
\hline Year & & & & & 0.385 & & 0.3 \\
\hline 2016 & 317 & 36.3 & 1.2 & 1.4 & 0.3 \\
\hline 2017 & 274 & 31.4 & 1.0 & 1.1 & 0.3 & 0.4 \\
\hline 2018 & 283 & 32.4 & 1.0 & 1.3 & 0.3 & 0.4 \\
\hline Total & 874 & 100.0 & 1.0 & 1.3 & 0.3 & 0.4 \\
\hline $\begin{array}{l}\text { Abbreviations: BMI, body mass index; IQR, interquartile range; NNAL, 4-(methylnitrosamino)-1-(3- } \\
\text { pyridyl)-1-butanol; S.D., standard deviation; SHSE, secondhand smoke exposure }\end{array}$ \\
\hline * Age is a continuous variable and N=Mean, \%=standard deviation.
\end{tabular}

Table 2. Association between the concentrations of urinary NNAL and cotinine in children and parents' smoking status 


\begin{tabular}{|c|c|c|c|c|c|c|}
\hline \multirow[t]{3}{*}{ Variables } & \multicolumn{6}{|c|}{ Log-transformed model } \\
\hline & \multicolumn{3}{|l|}{ NNAL } & \multicolumn{3}{|c|}{ Cotinine } \\
\hline & B & S.E. & $P$ value & B & S.E. & $P$ value \\
\hline \multicolumn{7}{|c|}{ Parents' smoking status } \\
\hline Smoker & 0.482 & 0.065 & $<0.001$ & 0.472 & 0.06 & $<0.001$ \\
\hline Non-smoker & Ref. & & & Ref. & & \\
\hline \multicolumn{7}{|l|}{ Children } \\
\hline \multicolumn{7}{|l|}{ Sex } \\
\hline Male & 0.159 & 0.062 & 0.010 & 0.110 & 0.054 & 0.044 \\
\hline Female & Ref. & & & Ref. & & \\
\hline Age* $^{*}$ & -0.036 & 0.018 & 0.046 & -0.013 & 0.016 & 0.399 \\
\hline \multicolumn{7}{|l|}{ BMI } \\
\hline Underweight & -0.039 & 0.072 & 0.589 & -0.055 & 0.064 & 0.390 \\
\hline Normal & Ref. & & & Ref. & & \\
\hline Overweight & 0.341 & 0.169 & 0.044 & 0.253 & 0.148 & 0.088 \\
\hline \multicolumn{7}{|l|}{ SHSE (house) } \\
\hline Yes & 0.441 & 0.193 & 0.023 & 0.532 & 0.169 & 0.002 \\
\hline No & Ref. & & & Ref. & & \\
\hline \multicolumn{7}{|l|}{ SHSE (public) } \\
\hline Yes & 0.026 & 0.136 & 0.846 & -0.106 & 0.119 & 0.375 \\
\hline No & Ref. & & & Ref. & & \\
\hline \multicolumn{7}{|l|}{ Parents } \\
\hline \multicolumn{7}{|c|}{ Household income } \\
\hline Q1 (low) & 0.197 & 0.102 & 0.053 & 0.146 & 0.089 & 0.102 \\
\hline Q2 & 0.165 & 0.088 & 0.062 & 0.024 & 0.078 & 0.753 \\
\hline Q3 & 0.041 & 0.088 & 0.637 & 0.044 & 0.077 & 0.571 \\
\hline Q4 (high) & Ref. & & & Ref. & & \\
\hline \multicolumn{7}{|c|}{ Type of housing } \\
\hline Apartment & -0.315 & 0.076 & $<0.001$ & -0.219 & 0.067 & 0.001 \\
\hline
\end{tabular}




\begin{tabular}{|c|c|c|c|c|c|c|}
\hline House & Ref. & & & Ref. & & \\
\hline \multicolumn{7}{|l|}{ Region } \\
\hline Urban area & 0.215 & 0.074 & 0.004 & 0.048 & 0.065 & 0.457 \\
\hline Rural area & Ref. & & & Ref. & & \\
\hline \multicolumn{7}{|l|}{ Age (father), years } \\
\hline$<40$ & 0.066 & 0.159 & 0.679 & -0.294 & 0.139 & 0.035 \\
\hline $40-49$ & 0.134 & 0.139 & 0.336 & -0.246 & 0.122 & 0.044 \\
\hline$\geq 50$ & Ref. & & & Ref. & & \\
\hline \multicolumn{7}{|l|}{ Age (mother), years } \\
\hline$<40$ & 0.436 & 0.266 & 0.101 & 0.338 & 0.233 & 0.148 \\
\hline $40-49$ & 0.460 & 0.259 & 0.076 & 0.337 & 0.227 & 0.138 \\
\hline$\geq 50$ & Ref. & & & Ref. & & \\
\hline \multicolumn{7}{|l|}{ Education level (father) } \\
\hline Middle school or lower & 0.317 & 0.163 & 0.052 & 0.411 & 0.143 & 0.004 \\
\hline High school & 0.334 & 0.080 & $<0.001$ & 0.143 & 0.070 & 0.042 \\
\hline College or higher & Ref. & & & Ref. & & \\
\hline \multicolumn{7}{|l|}{ Education level (mother) } \\
\hline Middle school or lower & 0.915 & 0.185 & $<0.001$ & 0.451 & 0.162 & 0.006 \\
\hline High school & 0.035 & 0.078 & 0.650 & -0.062 & 0.068 & 0.365 \\
\hline College or higher & Ref. & & & Ref. & & \\
\hline \multicolumn{7}{|c|}{ Private health insurance (father) } \\
\hline Yes & 0.078 & 0.201 & 0.699 & 0.120 & 0.176 & 0.497 \\
\hline No & Ref. & & & Ref. & & \\
\hline \multicolumn{7}{|c|}{ Private health insurance (mother) } \\
\hline Yes & -0.034 & 0.176 & 0.845 & -0.118 & 0.154 & 0.444 \\
\hline No & Ref. & & & Ref. & & \\
\hline \multicolumn{7}{|l|}{ Drinking status (father) } \\
\hline Yes & -0.012 & 0.083 & 0.885 & -0.023 & 0.073 & 0.752 \\
\hline No & Ref. & & & Ref. & & \\
\hline
\end{tabular}




\begin{tabular}{|c|c|c|c|c|c|c|}
\hline Yes & 0.030 & 0.066 & 0.648 & -0.144 & 0.058 & 0.013 \\
\hline No & \multicolumn{3}{|l|}{ Ref. } & \multicolumn{3}{|l|}{ Ref. } \\
\hline \multicolumn{7}{|l|}{ Year } \\
\hline 2016 & \multicolumn{3}{|l|}{ Ref. } & \multicolumn{3}{|l|}{ Ref. } \\
\hline 2017 & -0.105 & 0.076 & 0.168 & 0.001 & 0.067 & 1.000 \\
\hline 2018 & -0.042 & 0.076 & 0.582 & 0.064 & 0.066 & 0.337 \\
\hline \multicolumn{7}{|c|}{$\begin{array}{l}\text { Abbreviations: BMI, body mass index; NNAL, 4-(methylnitrosamino)-1-(3-pyridyl)-1-butanol; Ref., } \\
\text { reference group of parents who are non-smokers; S.E., standard error; SHSE, secondhand smoke } \\
\text { exposure. }\end{array}$} \\
\hline
\end{tabular}

Table 3. Subgroup analysis of log-transformed NNAL and cotinine values according to parents' smoking status 


\begin{tabular}{|c|c|c|c|c|c|c|c|}
\hline \multirow{3}{*}{$\begin{array}{l}\text { Parents' smoking } \\
\text { status }\end{array}$} & \multirow{3}{*}{$\begin{array}{l}\text { Non- } \\
\text { smoking }\end{array}$} & \multicolumn{6}{|c|}{ Smoking } \\
\hline & & \multicolumn{3}{|l|}{ NNAL } & \multicolumn{3}{|c|}{ Cotinine } \\
\hline & & B & SE & $\begin{array}{l}P \\
\text { value }\end{array}$ & B & SE & $\begin{array}{l}P \\
\text { value }\end{array}$ \\
\hline \multicolumn{8}{|l|}{ Children } \\
\hline \multicolumn{8}{|l|}{ Sex } \\
\hline Male & Ref. & 0.535 & 0.089 & $<0.001$ & 0.597 & 0.079 & $<0.001$ \\
\hline Female & Ref. & 0.351 & 0.099 & $<0.001$ & 0.276 & 0.083 & 0.001 \\
\hline \multicolumn{8}{|l|}{ BMI } \\
\hline Underweight & Ref. & 0.489 & 0.084 & $<0.001$ & 0.421 & 0.071 & $<0.001$ \\
\hline Normal & Ref. & 0.450 & 0.114 & $<0.001$ & 0.490 & 0.102 & $<0.001$ \\
\hline Overweight & Ref. & 0.980 & 0.681 & 0.184 & 1.885 & 0.559 & 0.008 \\
\hline \multicolumn{8}{|l|}{ Parents } \\
\hline \multicolumn{8}{|l|}{ Household income } \\
\hline Q1 (low) & Ref. & 0.762 & 0.167 & $<0.001$ & 0.634 & 0.155 & $<0.001$ \\
\hline Q2 & Ref. & 0.383 & 0.137 & 0.006 & 0.515 & 0.102 & $<0.001$ \\
\hline Q3 & Ref. & 0.363 & 0.136 & 0.008 & 0.268 & 0.125 & 0.033 \\
\hline Q4 (high) & Ref. & 0.458 & 0.106 & $<0.001$ & 0.412 & 0.106 & $<0.001$ \\
\hline \multicolumn{8}{|l|}{ Type of housing } \\
\hline Apartment & Ref. & 0.440 & 0.071 & $<0.001$ & 0.390 & 0.063 & $<0.001$ \\
\hline House & Ref. & 0.520 & 0.167 & 0.002 & 0.618 & 0.140 & $<0.001$ \\
\hline \multicolumn{8}{|l|}{$\begin{array}{l}\text { Education level } \\
\text { (father) }\end{array}$} \\
\hline $\begin{array}{l}\text { Middle school or } \\
\text { lower }\end{array}$ & Ref. & 0.531 & 0.459 & 0.261 & 0.926 & 0.567 & 0.118 \\
\hline High school & Ref. & 0.783 & 0.157 & $<0.001$ & 0.793 & 0.120 & $<0.001$ \\
\hline College or higher & Ref. & 0.356 & 0.076 & $<0.001$ & 0.337 & 0.069 & $<0.001$ \\
\hline \multicolumn{8}{|l|}{$\begin{array}{l}\text { Education level } \\
\text { (mother) }\end{array}$} \\
\hline $\begin{array}{l}\text { Middle school or } \\
\text { lower }\end{array}$ & Ref. & 1.613 & 0.934 & 0.145 & 1.491 & 0.894 & 0.156 \\
\hline High school & Ref. & 0.535 & 0.129 & $<0.001$ & 0.475 & 0.120 & $<0.001$ \\
\hline
\end{tabular}


Abbreviations: BMI, body mass index; NNAL, 4-(methylnitrosamino)-1-(3-pyridyl)-1-butanol; Ref., reference group of parents who are non-smokers; S.E., standard error.

\section{Figures}

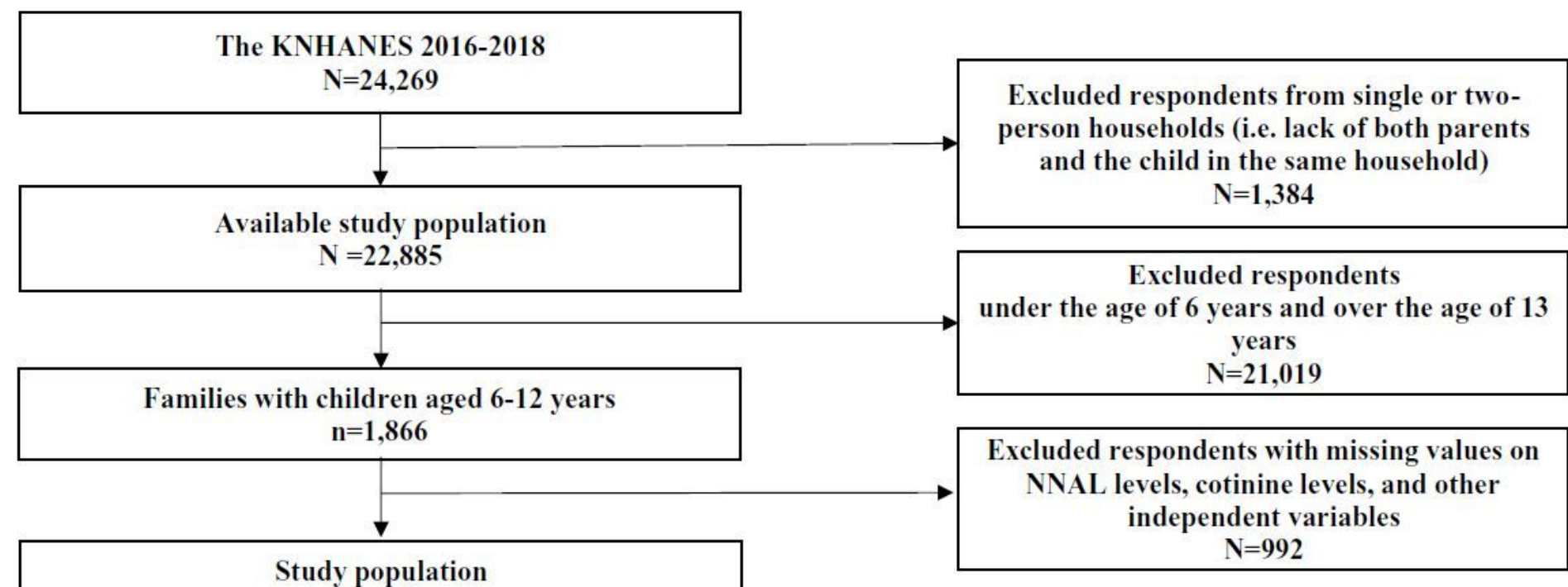

\section{Figure 1}

Participant flowchart. KNHANES, Korea National Health and Nutrition Examination Survey; NNAL, 4(methylnitrosamino)-1-(3-pyridyl)-1-butanol.
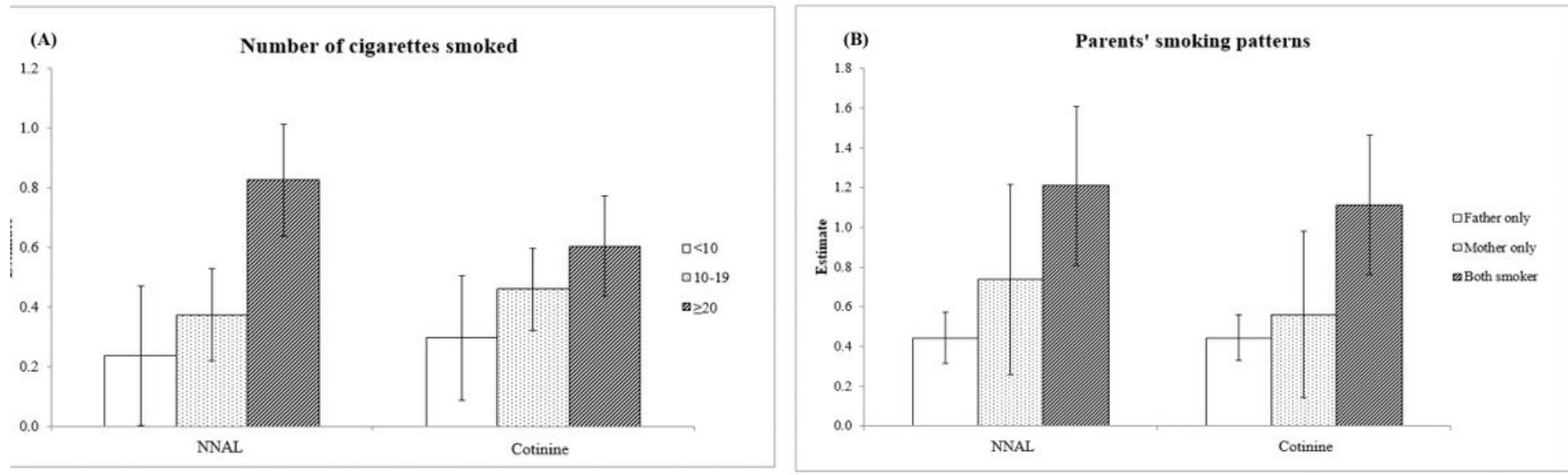
Association of children's 4-(methylnitrosamino)-1-(3-pyridyl)-1-butanol (NNAL) and cotinine concentrations with the number of cigarettes smoked by the parents (a) and smoking pattern (b).

Adjusted for children's sex, age, body mass index, secondhand smoke exposure (house), and secondhand smoke exposure (public), and for parents' household income, type of housing, region, age, education level, private health insurance, drinking status, and year of evaluation. The reference group is the group of parents who are non-smokers.

\section{Supplementary Files}

This is a list of supplementary files associated with this preprint. Click to download.

- supplementary.pdf 